\title{
Social Communication Across the Lifespan: The Influence of Empathy
}

Kathrin Rothermich ${ }^{1}$, Cristal Giorio Jackson ${ }^{2}$, Lindsay Leonard ${ }^{1}$, Sharon Falkins ${ }^{3}$, and Angela Roberts $^{4}$

${ }^{1}$ Department of Communication Sciences and Disorders, East Carolina University, Greenville, North Carolina

${ }^{2}$ Department of Psychiatry, Washington University School of Medicine, St. Louis, Missouri

${ }^{3}$ Department of Psychology, East Carolina University, Greenville, North Carolina

${ }^{4}$ Department of Communication Sciences and Disorders, Northwestern University, Chicago,

Illinois

Corresponding author:

Kathrin Rothermich

Department of Communication Science and Disorders

East Carolina University

600 Moye Blvd., Mail stop 668

Greenville, NC 27858

Email: rothermichk17@ecu.edu

Phone: (252)7442329

\section{AUTHOR'S NOTE:}

We would like to thank Havan Harris, Susan Bobb, and Moritz Dannhauer and two anonymous reviewers for valuable feedback on this manuscript.

Declarations of interest: none. 
Abstract

Studies testing the effects of aging on social communication have mainly focused on one sensory modality, for example using written vignettes. In the current study, we examine the effect of healthy aging, empathy, and anxiety traits on a social communication task using video stimuli that reflect real-world interactions. By means of an online recruitment platform, we asked young, middle-aged, and older adults between the ages 18 and $76(N=100)$ to evaluate videos of actors using different forms of literal and nonliteral language, such as sarcasm or teasing. The participants' task was to infer the speakers' belief and the speaker's intention, and we also collected data on self-reported social anxiety levels and empathy. Older participants demonstrated lower accuracy in discriminating nonliteral from literal interactions compared to younger and middle-aged groups, while older adults with higher perspective-taking scores were more accurate at identifying teasing as nonliteral. This effect was partially mediated by empathy. When evaluating speaker intentions, older adults judged sarcasm as friendlier compared to literal negative utterances. Our results expand on age-related similarities and differences in evaluating speaker intentions and we discuss our results in the context of the Tinge Hypothesis. Keywords: aging, social cognition, nonliteral language, pragmatics, empathy, anxiety 
Social Communication Across the Lifespan: The Influence of Empathy

The ability to accurately process social information during communication is important to be able to interpret other peoples' feeling, intentions, and attitudes. Understanding what other people think and feel enables us to navigate social environments and helps us to partake in meaningful interactions and to maintain social relationships. The maintenance of functional communication skills over the life span is essential and a crucial social determinant of healthy aging (Yorkston, Bourgeois, \& Baylor, 2010). Social communication difficulties can limit functional capacities and quality of life (Phillips, Allen, Bull, Hering, Kliegel, \& Channon, 2015) and might lead to substantial declines in social participation (Bailey, Henry and von Hippel, 2008). Thus, it is important to determine the factors that underlie the effects of aging on social communication skills.

The current study examines high-level, pragmatic language processing in the form of nonliteral language (e.g., sarcasm) in a naturalistic, dynamic language context. Nonliteral language is omnipresent in daily life and requires a cautious interpretation of a speaker's intention, the integration of linguistic and paralinguistic information, as well as emotion reading and perspective taking. An important aspect of nonliteral language is its multimodality speakers use an array of visual and auditory cues to express indirect meanings. In most cases, the recognition of nonverbal information such as tone of voice, facial expression, and body language is crucial to understand nonliteral utterances. Deficits in understanding nonliteral language occur in many neurological, developmental, and psychiatric disorders (Cassel, McDonald, Kelly, \& Togher, 2016) and can lead to difficulties interacting with friends and family, functioning in a working environment, and having an active social life (Holtgraves \& Cadle, 2016). 


\section{Models on nonliteral language processing}

Nonliteral language comprehension requires perspective taking and ignoring the literal meaning of a sentence; multiple sources of information need to be integrated, including social context and the speaker's emotional state. The exact nature of nonliteral language comprehension has been a matter of debate, and several models such as the StandardPragmatic Model (Grice, 1975, 1978), the Graded Salience Hypothesis (Fein, Yeari, \& Giora, 2015; Giora, Fein, \&, Schwartz, 1998, Giora et al., 2007), and the Direct Access Hypothesis (Gibbs, 1994) have been proposed to describe the process. While testing these theories has led to important insights, most of them ignore the social functions of nonliteral language. The Tinge Hypothesis is particularly relevant for the current study since it assumes social functions related to sarcasm and teasing, such as the proposed muting function of sarcasm (Dews et al., 1995; Dews \& Winner, 1995). It states that the positive surface meaning of a sarcastic remark can make it appear more positive than a literal negative statement, thereby muting the negative judgement. The idea is that a sarcastic utterance tinges the interpretation of the speaker's intended negative meaning and leads to an overall more positive interpretation.

While several studies have confirmed the Tinge Hypothesis (Dews \& Winner 1997, Dews \& Winner 1999; Pomareda et al., 2019; Schwoebel, Dews, Winner, \& Srinivas, 2000), others have found that when sarcasm functions as commentary on morally combative behavior (e.g., Colston, 1997) or is uttered in the context of hostile discourses (Bowes \& Katz, 2011), it can be perceived as more disrespectful than literal criticisms. Additionally, when using written materials, Pomareda et al. (2019) found the muting function only for younger and not older adults. It is unclear if the muting function of sarcasm occurs in all circumstances (see MewhortBuist \& Nilsen, 2019), and most studies on the Tinge Hypothesis included written materials (Pomareda et al., 2019; Thompson, Mackenzie, Leuthold \& Filik, 2016; Schwoebel et al., 2000), leaving out prosody and nonverbal cues that contribute to the complexity of nonliteral language 
in everyday communication. The current experiment will test the Tinge Hypothesis using dynamic, audio-visual stimuli.

\section{The RISC database}

Given the importance of understanding speaker intentions in everyday life, there is a need for research tools that are 1) as close to real interactions as possible and 2) offer an array of verbal and nonverbal social cues, such as prosody, facial expressions, and body language. We developed the Relational Inference of Social Communication database (RISC; Rothermich \& Pell, 2015) to provide ecologically valid video stimuli to study social communication in healthy and brain-damaged individuals. The RISC database entails 600 dynamic video vignettes of actors in everyday type scenarios employing realistic nonverbal social cues; it focuses on different types of speaker intentions such as sincere, teasing, prosocial lies, and sarcasm.

An advantage of the RISC database is that the lexical-semantic content of different statements is highly controlled, and the speaker's intention must be deducted from nonverbal cues, such as facial expressions, tone of voice, and body language. For the current experiment, we focus on literal positive, literal negative, sarcastic and teasing interactions. Teasing is described here as a negatively worded statement that is meant to be taken positively, accompanied by friendly facial and vocal cues (Keltner, Capps, Kring, Young, \& Heerey, 2001). In the RISC database, teasing mainly manifests as an "ironic compliment," for example somebody saying, "You did a terrible job!" to a person who actually did a great job. Teasing statements are typically exchanged between close friends and are intended to communicate humorous aggression and affiliation (Fein, Bergerbest, \& Gioar, 2014; Lampert \& Ervin-Tripp, 2006; Seckman \& Couch, 1989). Sarcasm, on the other hand, typically comprises a positive statement that has a negative or criticizing intention. It is commonly accompanied by acoustic markers such as changes in intonation (Cheang \& Pell, 2008) and body language, such as eye rolling (Attardo, Eisterhold, Hay, \& Poggi, 2003). The suggested social functions of sarcasm range from demonstrating a form of criticism, alleviating the aggressiveness of a critical 
statement, or being humorous (e.g., Caucci \& Kreuz, 2012; Dews, Kaplan, \& Winner, 1995; Jorgensen, 1996). Within the RISC inventory, teasing and sarcasm represent the nonliteral statements that are put in contrast to literal positive and negative statements. Importantly, literal negative and teasing statements as well as literal positive and sarcastic statements have identical lexical content, and the speakers' true intentions are only communicated via nonverbal cues.

\section{Aging and social communication}

The recognition of nonverbal social and emotional cues, such as the processing of emotional prosody (e.g., Allen and Brosgole, 1993; Kiss and Ennis, 2001; Mitchell, 2007; Orbelo et al., 2003, Orbelo et al., 2005) and pragmatic forms of meaning (for a review see Phillips, Slessor, Bailey, \& Henry, 2014), have been shown to change with age. Specifically, the processing of humor and nonliteral language has been reported to decline in later stages of life (Halberstadt, Ruffman, Murray, Taumoepeau, \& Ryan, 2011; Phillips et al., 2015; Shammi, \& Stuss, 2003; Uekermann, Thoma, \& Daum, 2008). In a recent study testing age-related differences in the perception of emotion in speech, Ben-David (2019) and colleagues showed that older adults often underestimate the emotional content of speech and differences in attending to semantics when compared to prosodic elements. If this is the case, sarcasm and teasing can present challenges to older participants, as has been found in the study by Phillips et al. (2015). In their study, older adults were less successful in comprehending both written and audio-visual sarcastic exchanges when compared to younger and middle-aged adults. Pomareda et al. (2019) found an effect of healthy aging on the understanding of nonliteral language, with a particular difficulty with teasing statements.

Deficits that lead to improper interpretation of nonliteral language can lead to difficulties communicating and interacting in everyday social settings (Elamin, Pender, Hardiman \& Abrahams, 2012). Thus, it is important to study how aging impacts the comprehension of nonliteral language in healthy and brain-damaged populations, which in turn will allow the 
development of better diagnostic and therapeutic tools that focus on these skills. However, some studies have also reported a preserved or improved ability to decode social and emotional communication cues across the lifespan (e.g., Happé, Winner, \& Brownell, 1998; Grainger, Henry, Naughtin, Comino, \& Dux, 2018; Richter \& Kunzmann, 2011).

Additionally, several studies have shown a tendency of older adults to process ambiguous or conflicting information as positive (positivity bias) and to ignore negative information (e.g., Mather \& Carstensen, 2013; Pomareda et al., 2019; Reed \& Carstensen, 2012). Di Domenico and colleagues (2015) found that older adults recognized positive dynamic facial expressions faster than negative ones, while no such effect was found for younger adults. However, data against the positivity bias was provided by Pomareda et al. (2019), who found that older adults had problems recognizing negative affect when encountering sarcasm but also with identifying a positive intention when reading teasing vignettes. Together, research findings suggest a complex pattern of life span differences in the ability to accurately perceive another's emotions and intentions.

\section{Individual differences}

Social cognition skills related social communication, such as Theory of Mind (ToM; Happe, Winner \& Brownell, 1998; Maylor et al., 2002; Jarvis \& Miller, 2017) and empathy (Richter \& Kunzmann, 2011; Beadle et al., 2012; Beadle et al., 2013), have been debated as either being diminished, preserved or improved across the life span. For example, a study by Beadle and colleagues (2015) revealed that older adults often show greater prosocial behaviors and seem more motivated to show empathy and help others when compared to younger adults. However, a study by Bailey and Henry (2008) found lower self-reported and performance-based cognitive empathy scores in older adults compared to younger adults, while they observed no difference in affective empathy between age groups. They also show that older adults, compared to younger adults, are often less involved in social activities, and that cognitive empathy partial mediates this association, which speaks for a role of cognitive empathy in social 
functioning (Bailey \& Henry, 2008). While the role of ToM and empathy has been the focus of many studies on social cognition and aging, there is less data on the influence of other individual differences, such as social anxiety. Participants with high levels of social anxiety show a tendency to rate ambiguous facial expressions as negative (Winton, Clark, \& Edelmann, 1995) and often rate socially relevant stimuli as more negative than controls (Coles et al., 2008); this may have an impact on how socially anxious individuals interpret social intentions such as teasing and sarcasm. In their study, Milanowicz, Tarnowski and Bokus (2017) showed that anxiety can be a predictor of nonliteral language comprehension, while another study revealed that low empathy scores predict lower accuracy in identifying speaker intentions (Jakobson, Pearson, Kozuba, Hare, \& Rigby, 2018). Thus, the extent to which anxiety and empathy are meaningful factors in processing social intention is a matter of debate.

\section{The current study}

While the RISC database has been validated to capture social communication abilities in young adults (Rothermich \& Pell, 2015), there is currently no data available on how middle-aged and older participants perform on tasks involving dynamic, audio-visual stimuli. The database has been developed to provide a highly constructive tool on the interpretation of speaker intentions in both healthy adults and clinical populations, such as Parkinson's Disease or People with Aphasia. Given the age range associated with these specific populations, gaining information about how participants in different age groups react to these types of stimuli is crucial. Besides the age of participants, the RISC allows us to study the influence of empathy and anxiety on social communication using dynamic, audio-visual stimuli. Our three main predictions are that: (1) the ability to comprehend and evaluate nonliteral language is reduced in older adults compared to younger and middle-aged adults (Phillips et al., 2015; Pomareda et al., 2019); (2) according to the Tinge Hypothesis, sarcastic utterances will be perceived as friendlier when compared to literal negative utterances (Dews \& Winner, 1995; Pexman \& Olineck, 2002; but see also Colston, 1997); (3) measures of empathy and social anxiety mediate the response 
patterns when evaluating social intentions across the life span (Milanowicz et al., 2017; Phillips et al., 2015).

\section{Material and Methods}

\section{Participants}

In total, 119 adults (see Table 1 for details) took part in the current study. Inclusion criteria included English as native language, a minimum of 18 years of age, and participants needed to live in the USA at time of testing. Of those participants, 19 had to be excluded due to self-reported hearing problems $(n=16)$, self-reported dementia $(n=1)$, and missing data $(n=2)$. Of the remaining 100 participants, 38 were grouped as young adults (22 female, age 18-39), 29 were labeled middle-aged adults (17 female, age 40-59), and 33 were referred to as older adults (21 female, age 60-79). Age range cutoffs for the three groups were derived from previous literature (Phillips et al., 2015) assessing social decoding in a life span sample.

Table 1. Participant characteristics.

\begin{tabular}{|c|c|c|c|c|c|c|c|c|c|c|c|c|}
\hline & \multicolumn{2}{|l|}{ YA } & \multicolumn{2}{|l|}{ MA } & \multicolumn{2}{|l|}{ OA } & \multicolumn{2}{|c|}{ MA vs. YA } & \multicolumn{2}{|c|}{ MA vs. OA } & \multicolumn{2}{|c|}{ OA vs. YA } \\
\hline & Mean & $S D$ & Mean & $S D$ & Mean & $S D$ & $t$-value & $97.5 \% \mathrm{Cl}$ & $t$-value & $97.5 \% \mathrm{Cl}$ & $t$-value & $97.5 \% \mathrm{Cl}$ \\
\hline Sample Size & 38 & $N A$ & 29 & $N A$ & 33 & $N A$ & $N A$ & NA & NA & NA & NA & NA \\
\hline $\operatorname{Sex}(F / M)$ & $21 / 17$ & $N A$ & $17 / 12$ & $N A$ & $20 / 13$ & $N A$ & $N A$ & NA & NA & NA & NA & NA \\
\hline Age (yrs) & 27.89 & 5.02 & 47.03 & 5.70 & 64.18 & 4.67 & $N A$ & NA & NA & NA & NA & NA \\
\hline Education (yrs) & 12.6 & 3.65 & 13.8 & 3.64 & 13.7 & 3.36 & $18.80^{* * *}$ & {$[-4.5,-3.6]$} & $2.38^{*}$ & {$[-.28,-.02]$} & $16.66^{\star * *}$ & {$[.92,1.16]$} \\
\hline IRI - PD & 13.8 & 8.1 & 12.3 & 5.1 & 9.6 & 5.6 & $-12.22^{\star * *}$ & {$[1.2,1.6]$} & $22.12^{* \star *}$ & {$[-2.9,-2.4]$} & $-35.99^{* * *}$ & {$[-4.4,-3.9]$} \\
\hline IRI - PT & 19.6 & 6.1 & 18.3 & 4.6 & 18.2 & 6.0 & $-12.71^{* * *}$ & {$[1.1,1.5]$} & 1.18 & {$[-.33, .08]$} & $-14.24^{* * *}$ & {$[-1.6,-1.2]$} \\
\hline IRI - EC & 18.8 & 6.7 & 17.6 & 5.8 & 17.1 & 4.6 & $-11.53^{* * *}$ & {$[1.0,1.4]$} & $4.87^{* * *}$ & {$[.74,-.31]$} & $-16.96^{* * *}$ & {$[-1.9,-1.5]$} \\
\hline IRI - FS & 18.6 & 6.7 & 17.7 & 4.7 & 16.3 & 4.8 & $-8.39^{* \star *}$ & {$[.64,1.03]$} & $13.41^{* * *}$ & {$[-1.6,-1.2]$} & $-22.82^{* * *}$ & {$[-2.4,-2.04]$} \\
\hline STATE & 35.5 & 10.8 & 32.3 & 10.6 & 30.4 & 8.3 & $-17.86^{\star * *}$ & {$[2.9,3.5]$} & $10.13^{* * *}$ & {$[-2.3,-1.5]$} & $-29.02^{* * *}$ & {$[-5.4,-4.7]$} \\
\hline TRAIT & 45.9 & 12.8 & 41.9 & 14.1 & 35.4 & 11.8 & $-17.60^{* * *}$ & {$[3.6,4.5]$} & $26.88^{* * *}$ & {$[-6.9,-5.9]$} & $-46.55^{\star * *}$ & {$[-10.9,-10.1]$} \\
\hline
\end{tabular}

Note. Descriptive information for all three age groups and scores for empathy (YO=younger adults, $\mathrm{MA}=$ middle-aged adults, $\mathrm{OA}=$ older adults, $\mathrm{PD}=$ Personal Distress, $\mathrm{PT}=$ Perspective Taking, $\mathrm{FS}=$ Fantasy Scale, EC = Empathic Concern) and anxiety (State-Trait Anxiety Scores). Asterisks indicate significance levels ( $n s=p>0.05 ;{ }^{*}=p \leq 0.05 ;{ }^{* *}=p \leq 0.01 ;{ }^{* * *}=p \leq 0.001$ ). 
All remaining participants self-reported the absence of a dementia diagnosis, a mild cognitive impairment diagnosis, and had intact or corrected visual and auditory functioning. The study was approved by the local ethics review board. Participants were recruited through Prolific Academia, a research participant recruiting database (http://prolific.ac), and participants gave consent via a digital signature before starting the experiment. They received $\$ 13.50$ as monetary compensation.

\section{Stimulus Materials, Task and Procedures}

In the first part of the experiment, all participants completed the Interpersonal Reactivity Index (IRI; Davis, 1983) to measure empathy on four subscales (perspective taking, fantasy, empathic concern, and personal distress), as well as the State-Trait Anxiety Inventory (STAI, Spielberger et al., 1983) to measure anxiety as a trait (TRAIT) or at time of testing (STATE). The video experiment was created and distributed using the Research Electronic Data Capture tool (REDCap), which is hosted online at Vanderbilt University (Harris et al., 2009). We presented participants with 192 videos (between 3 to 20 seconds in total length) taken from the RISC database depicting four different intentions: literal positive, literal negative, sarcasm and teasing. The 192 videos were chosen as a representative subset of the 600 videos available in the database in order to keep the length of the experiment manageable for the participants. In these videos, four native English-speaking actors (two male, two female; mean age in years $=19.50, S D=0.50$ ) perform the different communicative intentions. Each video includes two actors: one male/male, one female/male, and two female/male dyads.

In all videos, one actor poses a question to their paired interlocutor (e.g., "Would you like one of the cookies I just made?"), that is followed by a response from the second actor that could either be positive (“Mmmh, they look so good!") or negative (“They don't look very appetizing."; see Appendix for details). Positive responses were expressed in a literal positive manner or sarcastically, while negative responses were delivered in a literal negative (blunt) or teasing manner. The vignettes portrayed eleven different scenes (e.g., cookie, painting, or gift, 
see Appendix for more examples) in four possible relationships (couple, friends, boss/employee or colleagues; 4 intentions $\times 12$ scenes $\times 4$ relationships $=192$ trials). In order to provide a research inventory with high ecological validity, the RISC stimuli were designed to include a multitude of cues, such as facial expressions, gaze, gestures, and body language. The videos entail a number of spontaneous indicators corresponding to different intentions. For example, teasing utterances are usually accompanied by laughter, a common communicative strategy to assure that the negative content of the message is not taken literally (e.g., Lampert \& ErvinTripp, 2006). Similarly, the actors in the videos use an array of auditory cues to signal sarcasm, such as eye rolling, fake accents, and frequency changes (for more details, see Rothermich \& Pell, 2015).

To familiarize participants with the four actors, an introductory video (length=53 seconds) was presented at the beginning of the experiment. Before starting the experiment, participants completed a training task that including four practice trials. Participants watched each practice video trial and the task was to answer two questions after each video about speaker belief ("Did Anna like the cookies?" - Yes/No) and speaker intention ("How friendly was Anna trying to be?" 5-point Likert scale; 1 = not friendly at all, $5=$ very friendly). The speaker belief question taps into understanding the assertive intent of the speaker, i.e., what the speaker believes to be true, while the speaker intent question taps into the expressive intent of the speaker, i.e., their psychological state of mind (Haverkate, 1990). The experiment took approximately 75 minutes. We created four different lists consisting of all 192 stimuli that were presented in a pseudorandomized fashion to avoid order effects or differences due to fatigue. The participants had frequent options to take breaks.

\section{Data Analysis}

We used the Im function in R (Team \& R Development Core Team, 2018) to compute the differences between demographic and personality parameters and report p-values, t-values, and $97.5 \%$ confidence intervals $(\mathrm{Cl}$, see results in Table 1). To estimate the Cls, we used the 
standard method confint() in R. All other data were analyzed using Linear Mixed Effects Models in R (Team \& R Development Core Team, 2018) using the Ime4 package (Bates, Mächler, Bolker, \& Walker, 2014). While there is some debate in the literature on the best analytical approach to analyzing ordinal data such as Likert scales (Kizach, 2014), the risk of finding false positives (Type 1 error) is higher for ordinal data analysis methods compared to the linear mixed-effects method (Kizach, 2014; Norman, 2010). We applied the Satterthwaite (1946) approximation for computing $\mathrm{p}$-values for $t$-statistics, as implemented in the ImerTest package version 2.0-6 (Kuznetsova, Brockhoff, \& Christensen, 2017). Separate LME models were built for dependent variables of accuracy to identify speaker belief and ratings about the friendliness of the speaker. In all cases, we first defined a base model, which included only one random effect (Subject); refined models were then identified by performing comparisons using the ANOVA function in $\mathrm{R}$, and systematically comparing the full model with the model reduced by random and fixed effects in turn (for a similar approach, see Valuch, Pflüger, Wallner, Laeng, \& Ansorge, 2015). Our fixed effects (or independent variables) included Intention (LITERAL POSITIVE, LITERAL NEGATIVE, SARCASM, TEASING) and Age Group (YOUNGER AGE, MIDDLE-AGED, OLD AGE). Random effects included intercepts for Participants, Scenes, Lists, and by-subject slopes for the effect of Intention. Models were compared based on $X^{2}$, Akaike information criterion (AIC; Bozdogan, 1987), z-values, and $p$-values. The AIC is an estimator of the relative quality of statistical models for a given set of data and provides a means for model selection. Multiple comparisons were adjusted using Tukey's Multiple Contrasts (part of R package "emmeans"; Lenth, et al., 2018) for post-hoc testing. To examine the relationship among speaker belief, speaker intention, empathy and anxiety, we calculated Pearson's correlation coefficients across all variables (significance level $=p<0.05$ ).

Statistical tests of mediation were conducted using the mediation package in R (Tingley, Yamamoto, Hirose, Keele, \& Imai, 2013; see Phillips et al., 2015 for a similar approach). The basic steps for mediation analysis follow the recommendations made by Baron \& Kenny (1986) 
using three sets of regressions: 1 ) age $\rightarrow$ empathy score, 2) age $\rightarrow$ social inference (speaker belief or speaker intention), and 3) age + empathy score $\rightarrow$ social inference. In this model structure, if the effect of age on social inference completely disappears, empathy fully mediates between age and social inference (full mediation). If the effect of age on social inference measure still exists, but has an overall smaller magnitude, the interpretation would be that personality partially mediates between age and social inference (partial mediation).

\section{Results}

\section{Frequency analysis}

For the frequency analysis, we extracted the audio channel of the stimuli using Windows Movie Maker and saved the files as .wav. We then used the speech analysis software Praat (Boersma, 2002) to analyze mean fundamental frequency (f0) and frequency range for the part of the interaction that includes the literal or nonliteral answer. A custom Praat script was used to read out f0 (in $\mathrm{Hz}$ ) and we subsequently calculated mean fo and f0 range. The Praat script contains a loop that when it encounters an "undefined" f0 value, it skips to a nearby time point (in 0.01 second increments) and tries to determine fo once again. The results of this analysis are depicted in Table 2.

Table 2. Fundamental frequency means and range (in $\mathrm{Hz}$ ) averaged over all stimuli for male $(n=2)$ and female $(n=2)$ speakers by intention.

\begin{tabular}{lllll} 
& \multicolumn{2}{l}{ Mean f0 in $\mathrm{Hz}(S D)$} & f0 Range in $\mathrm{Hz}(S D)$ \\
\hline Intention & Male & Female & Male & Female \\
\hline Literal Positive & $200.92(68.59)$ & $319.00(68.76)$ & $336.60(132.92)$ & $321.43(118.18)$ \\
Sarcasm & $148.60(43.01)$ & $235.73(35.75)$ & $293.53(197.86)$ & $287.84(132.80)$ \\
Literal Negative & $141.65(29.06)$ & $261.35(59.18)$ & $235.61(130.57)$ & $270.79(122.95)$ \\
Teasing & $149.90(38.60)$ & $256.07(46.08)$ & $308.41(156.75)$ & $280.80(130.13)$ \\
\hline
\end{tabular}


We ran LME models for mean f0 and f0 range, including Scenes and Relationship as random factors and Intention as fixed factor. For mean frequency measures, the results show that including Intention significantly improves our model $\left(X^{2}=32.03, p<.001\right.$; AIC simple model = 2157; AIC intention model = 2131). Pairwise comparisons reveal a significantly higher mean f0 measure for LITERAL POSITIVE compared to LITERAL NEGATIVE $(\beta=58.34, t=4.54, p$ $<.001)$, SARCASTIC $(\beta=67.67, t=5.27, p<.001)$ and TEASING $(\beta=56.85, t=4.43, p$ $<.001)$ utterances. No other comparisons were significant. For f0 range, we find no differences for the model when including intention $(A I C=2430, p=0.056)$ when compared to a base model $(A / C=2432)$

\section{Speaker belief task}

Overall, participants had high accuracy scores when identifying speaker belief $(M=0.85$, $S D=0.35 ;$ see Figure 1$)$ and we found a significant difference $(X 2=848.91, p<.0001)$ when comparing the base model (only random factors Scene and Subject; $A / C=10278$ ) to an Intention model (Intention as fixed factor; $A / C=9436)$. Post-hoc comparisons showed that speaker belief for LITERAL NEGATIVE remarks was identified with higher accuracy than LITERAL POSITIVE $(\beta=0.04, z=6.48, p<.001)$, SARCASM $(\beta=0.03, z=4.34, p<.001)$, and TEASING $(\beta=0.16, z=28.20, p<.001)$ utterances. SARCASTIC scenes were identified more easily than LITERAL POSITIVE interactions $(\beta=0.01, z=2.91, p<.05)$ and TEASING $(\beta$ $=0.35, z=23.77, p<.001)$. Compared to LITERAL POSITIVE scenes participants were less accurate identifying TEASING interactions $(\beta=0.11, z=20.58, p<.001)$. There was no difference in accuracy between LITERAL POSITIVE and SARCASTIC scenes ( $p=0.1398)$. 
Figure 1 Boxplots of accuracy (in percentage) for each speaker intention and age group.

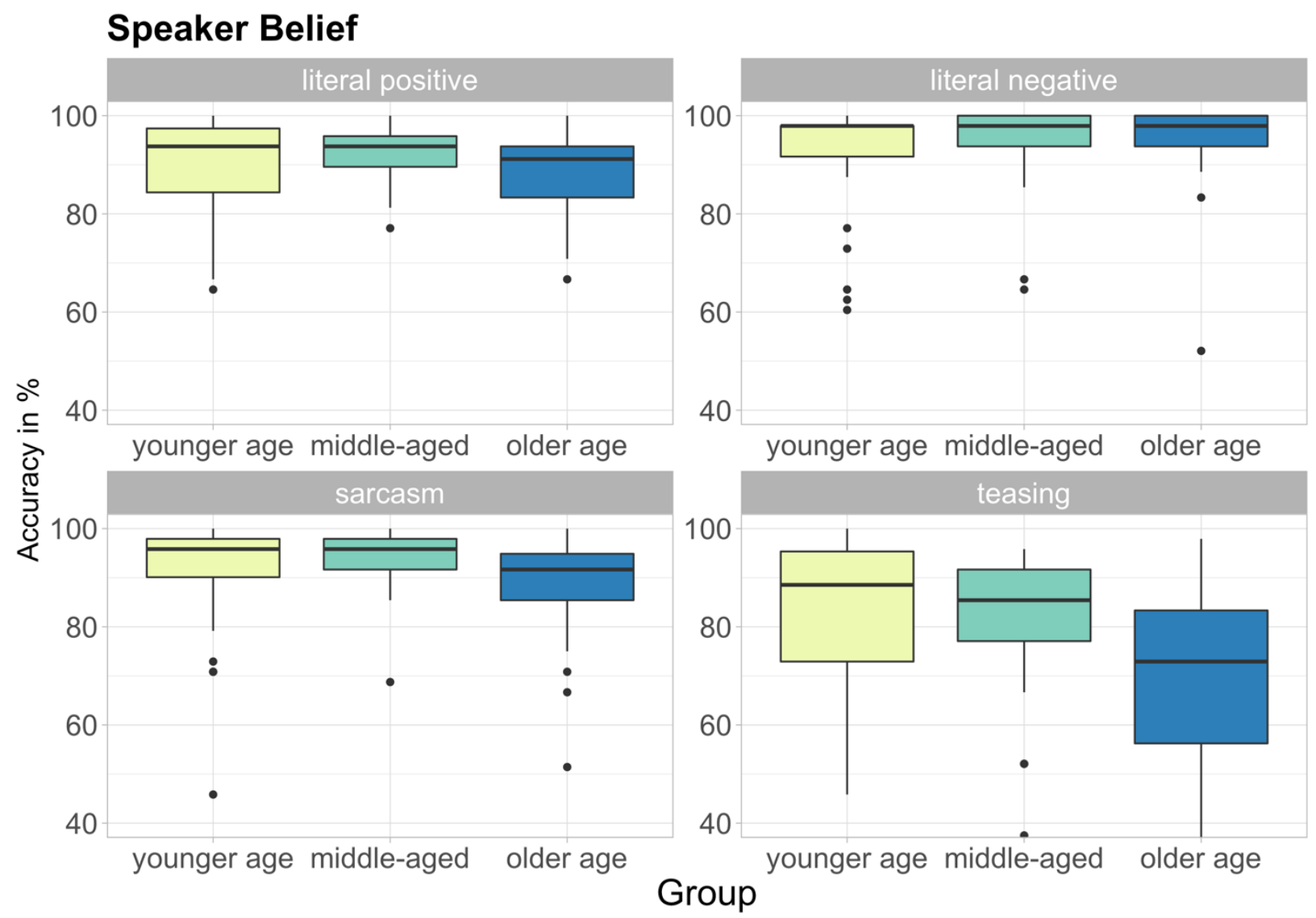

The intention model (Intention as fixed factor; $A / C=94356$ ) was significantly improved using a model containing an interaction between Intention and Age (see Figure 1; $A / C=9317$; $\left.x^{2}=134.93, p<.0001\right)$. Middle-aged participants have higher accuracy when compared to older age participants $(\beta=0.06, z=2.45, p<.05)$. Resolving the interaction for Age Group by Intention revealed significant differences in accuracy for SARCASM scenes between middleaged and older adults $(\beta=0.05, z=2.75 p<.05)$, with higher accuracy for middle-aged adults. The identification of speaker belief was also significantly different for TEASING interactions when comparing middle-aged and older adults (middle-age > older age; $\beta=0.11, t=5.41$, $p<.001$ ) as well as older and younger adults (younger age > older age; $\beta=0.10, t=4.91$, $p<.001)$. 
Speaker intention task

The Likert scale ratings on the friendliness of the speaker reveal a significant main effect of including Intention in the model $(A I C=47999 ; X 2=19964, p<.001 ;$ SARCASM $>$ LITERAL NEGATIVE > TEASING > LITERAL POSITIVE) versus the base model (only Scene and Subject as random factors; $A / C=67957)$. Post-hoc comparisons reveal higher friendliness ratings for LITERAL POSITIVE compared to LITERAL NEGATIVE $(\beta=1.87, z=118.29, p<.001)$, $\operatorname{SARCASM}(\beta=2.64, z=165.03, p<.001)$, and TEASING $(\beta=0.42, z=25.33, p<.001)$ scenes. Ratings were also higher for LITERAL NEGATIVE versus SARCASM interactions $(\beta=$ 0.76, $z=48.18, p<.001)$ as well as for TEASING compared to LITERAL NEGATIVE $(\beta=1.45$, $z=87.89, p<.001)$ and SARCASM $(\beta=2.21, z=133.39, p<.001)$ scenes.

Figure 2 Boxplots of friendliness ratings (Likert scale ratings) for each speaker intention and age group.

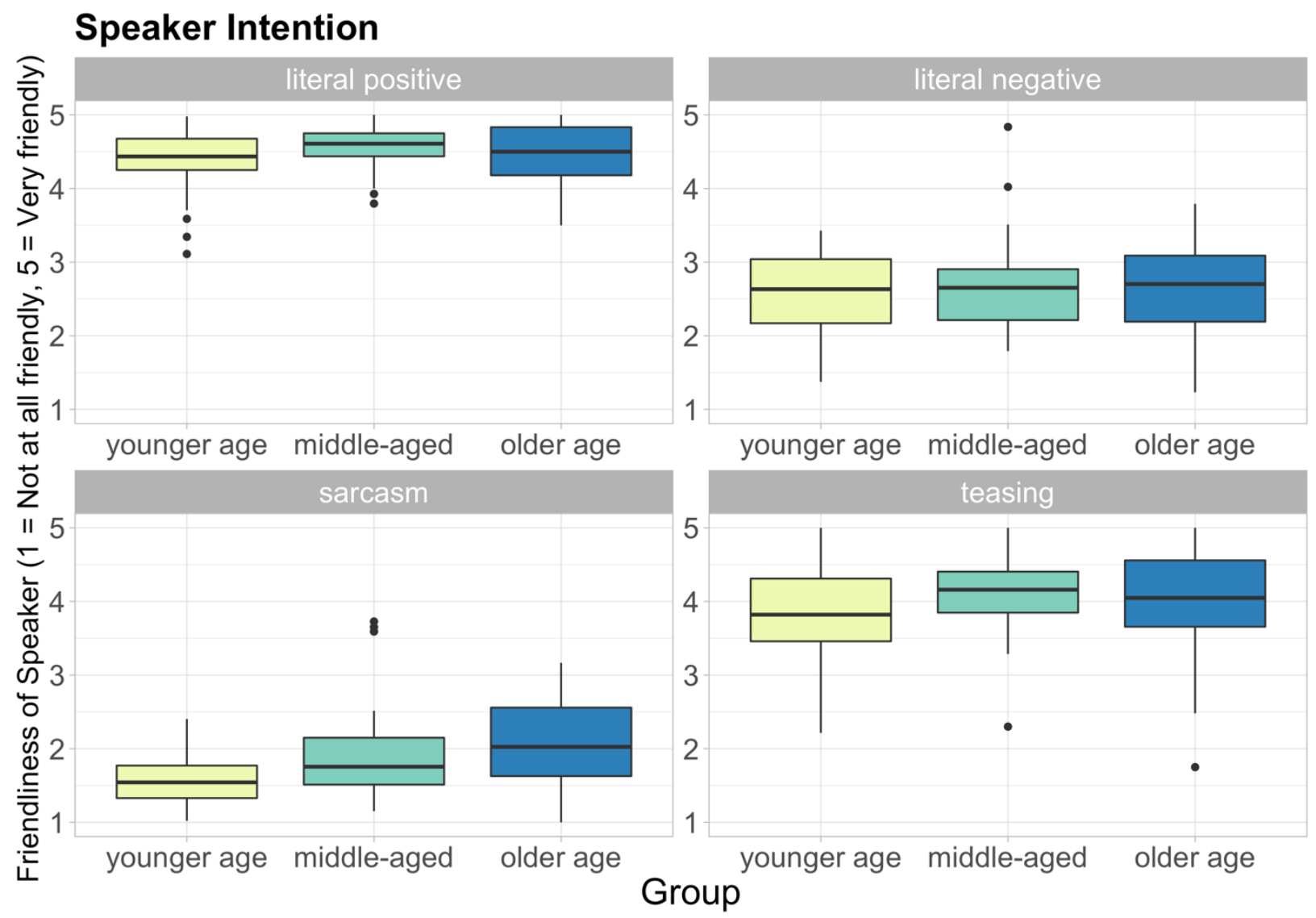


A significant effect was found when comparing the Intention model $(A I C=47811)$ with a model containing an interaction between Intention and Age (see Figure 2; $A / C=47999 ; X 2=$ 84.14, $p<.001)$. For SARCASTIC remarks, we found higher friendliness ratings for older compared to middle-aged $(\beta=0.21, z=2.53, p<.05)$ and younger participants $(\beta=51, z=$ $6.24, p<.001)$, and higher friendliness ratings for middle-aged compared to younger participants $(\beta=0.29, z=3.57, p<.01)$. Resolving the interaction for Age by Intention also revealed significantly higher friendliness ratings for TEASING interactions in middle-aged versus younger adults $(\beta=0.27, z=3.23, p<.01)$. To test the hypothesis put forward by the Tinge Hypothesis, we tested the difference between SARCASM and LITERAL NEGATIVE utterances in the three age groups separately. The results reveal that in all groups, LITERAL NEGATIVE statements where rated as friendlier than SARCASM statements (younger age: $\beta=0.95, z=$ 26.39, $p<.001$, middle-aged $\beta=0.72, z=20.76, p<.001$, older age: $\beta=0.57, z=36.18, p$ $<.001)$. Thus, the Tinge Hypothesis could not be confirmed.

\section{Empathy and anxiety correlations}

Pairwise comparisons for empathy and social anxiety measures are listed in Table 1. Overall, we find differences for all IRI subscales as well as TRAIT and STATE anxiety scores between all age groups. To examine what factors may have been associated with group differences in the ability to make social inferences, we correlated the questionnaire results for empathy and anxiety by age and found that accuracy identifying TEASING statements correlated positively with the IRI fantasy scale in the middle-aged group $(r=0.41, p=0.027$, and not in the other two groups, showing that middle-age participants with higher empathy scores were more accurate at this task. We also found that for SARCASM items, accuracy correlates positively with personal distress scores for older adults $(r=0.40, p=0.0182)$, revealing that higher self-reported personal distress leads to better accuracy at identifying sarcasm as nonliteral. For TEASING statements, perspective taking scores correlate positively 
with accuracy in older adults $(r=0.35, p=0.0442)$; older adults with higher perspective taking scores were more accurate at identifying teasing as nonliteral. No correlations were found for anxiety measures.

\section{Mediation analysis}

Based on the correlation results, we limited the mediation analysis to the predictor age group and the mediators to perspective taking and personal distress. We used the outcome variable accuracy/speaker belief. The mediation results are depicted in Figure 3. In a series of regressions, we tested whether the association between the predictor variable (age group) and the dependent variable (accuracy/speaker belief) is mediated by perspective taking and personal distress (see Phillips et al., 2015 and Pomareda et al. 2019 for a similar approach).

Figure 3 Results of the mediation analyses on the role of perspective taking (PT) and personal distress (PD) scores as mediators for the effect of age on identifying teasing and sarcasm as nonliteral. The numbers represent coefficients and the stars indicate the level of significance $(0$; “***' 0.001 ; ‘**' 0.01 ; ‘*' 0.05 ; ' ' $0.1 ;$;' 1 ). PT and PD partially mediate the age effect, as evident by the significance of both direct effects of age on accuracy (c) as well as indirect effects via PT and PD (c').

A)

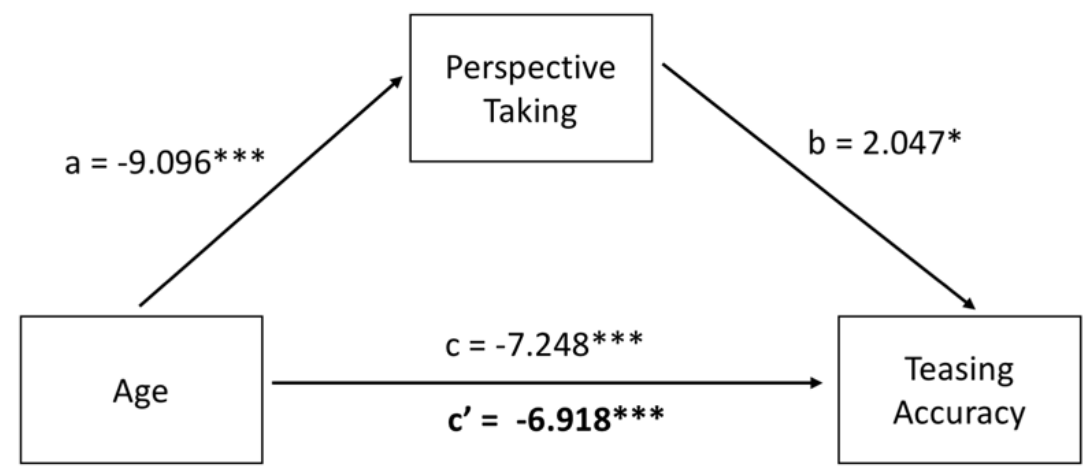

B)

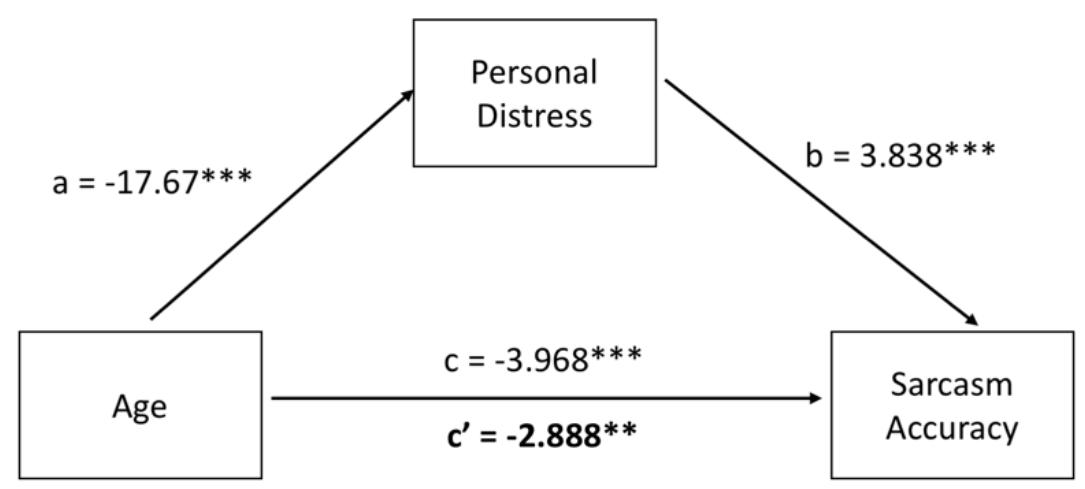


An initial regression tests the connection between the predictor and mediator variable (see path $a$ in Figure 3). The second step confirms the connection between the predictor variable and the dependent variable (see path $c$ in Figure 3). The final regression analysis simultaneously enters the mediator and predictor variables to explain variance in the dependent variable (paths $b$ and $c^{\prime}$ in Figure 3). Reductions from $c$ to $c^{\prime}$, once the mediator is entered, suggests a possible mediation effect. In a first step we tested the influence of perspective taking on age group differences in identifying speaker belief for teasing items. The results show that PT predicts accuracy of identifying speaker belief when entered along with age in the analysis (see path $b$ in Figure 3), and bootstrapping confirmed that partial mediation effect was present (Confidence interval: -0.0002 to 0.00 ). Similar results were found for PD as a potential mediator of the age effect (see Figure 3). Reductions from $c$ to $c$ ' suggest a possible mediation effect, which is supported by the confidence interval results $(-0.0004$ to 0.00$)$. These results suggest that age as a significant moderator of PT and PD and that PT and PD significantly moderate the relationship between age and teasing/sarcasm accuracy. In other words, as people age, they are more likely to have higher/lower scores on measures of PT and PD and have lower accuracies on recognizing teasing and sarcasm and that the ability to recognize either emotion is mediated by their PT and PD scores.

\section{Discussion}

The current study examined the influence of healthy aging on processing communicative intentions as well as the mediating influence of personality traits. Overall, older adults performed with lower accuracy scores when identifying nonliteral language compared to young and middle-aged adults, especially for teasing interactions. Additionally, older adults tended to interpret sarcastic interactions with a friendly demeanor compared to the other age groups. The Tinge Hypothesis could not be confirmed, as blunt (literal negative) remarks were rated as friendlier than sarcastic statements overall in all three age groups. Regarding empathic and social anxiety measures, only empathy correlated positively with how social intentions were 
evaluated. A partial mediation effect revealed the influence of age via perspective taking skills and personal distress on making social inferences, suggesting that empathy plays a role in agerelated changes of social communication.

Our data generally showed that participants were more accurate at identifying literal negative, literal positive, and sarcastic statements when compared to teasing statements. The higher accuracy for identifying literal statements has been found in earlier studies using the RISC inventory (Jakobson, Pearson, Kozuba, Harea, \& Rigby, 2018; Pell \& Rothermich, 2015) and can in part be explained by a so-called truth bias. This theory suggests that humans are inclined to operate on the default assumption that what the other person says is essentially honest (Levine, 2014). Thus, it is possible that participants were biased to assume the actor or actress is being literal, since that is perceived as the unmarked, default intention. We also found differences in accuracy between the three age groups, but only for nonliteral exchanges (i.e., sarcasm and teasing). This result corresponds to previous research and has been related to reduced abilities in identifying affective cues from faces, voices, and gestures, which seem to be mediated by emotion perception in older adults (Phillips et al., 2015). Our results on speaker intentions also revealed that older adults judge sarcasm as friendlier compared to middle-aged and younger adults, possibly due to difficulties in identifying the speakers' belief. If an older individual did not identify a sarcastic statement as conveying a negative attitude, they might have been more inclined to evaluate the statement as friendly. These results are in line with recent evidence showing that older adults have specific difficulties with teasing statements, and sometimes fail to identify the underlying intention (Pomareda et al., 2019).

It is also possible that our group of older adults based their decisions on different interpretations of communicative cues compared to the middle-aged or younger group, or that familiarity played a role. Giora (1997) suggested that sarcasm is more common than teasing in daily conversations and might therefore be harder to process cognitively (see also Pomareda et al., 2019). Overall, our findings indicate that older adults' may be more susceptible to decision- 
making difficulties in contexts that depend on accurately discerning social cues. The observed difficulties recognizing literal and nonliteral statements in older adults may also be explained by the "frontal aging hypothesis" (Uekermann et al., 2006; West \& Covell, 2001). It links deficits in working memory, inhibition, and abstract thinking to age-related plasticity changes in the prefrontal cortex, which are assumed to impact the ability to interpret facial expressions and other social cues (e.g., Shammi, \& Stuss, 2003; Sullivan \& Ruffman, 2004; Halberstadt et al., 2011; El Haj \& Antoine, 2018; Uekermann, Thoma, \& Daum, 2008). In the current study, we focused on differences related to personality traits. For future research, adding cognitive and neuropsychological measurements would allow to test the influence of specific cognitive domains on social communication in older adults.

The Tinge Hypothesis (Dews \& Winner, 1995) states that in comparison to literal negative statements, the positive surface meaning of a sarcastic statement serves to mute a negative intended meaning and is used in conversation to soften criticism. This hypothesis could not be confirmed in the current study, as participants in all three age groups rated literal negative statements as friendlier compared to sarcastic statements. This means that even though sarcastic statements are delivered with a positive surface meaning, the vocal and facial cues lead to a negative interpretation (see also Leggitt \& Gibbs, 2000). Additionally, it is possible that hyperbole and conventionalized politeness expressed in the sarcastic materials could end up intensifying the impoliteness of the message (Culpeper, 2015). Finally, Pexman and Olineck (2002) show that the "tinge" function may depend on the social inference task; if it involves judging listener impression (i.e., the social impression created by a statement) it might apply, while it might not come into play when one is considering speaker intent (i.e., the underlying motivation of the speaker). While our experiment focused on perceived friendliness, future studies should include tasks representing different types of listener impression (e.g., How polite?) or speaker intent (e.g., How mocking?). 
In the current study, older adults had significantly lower empathetic and social anxiety scores compared to younger and middle-aged adults. Due to the different components of empathy (emotional versus cognitive) and whether empathy is assessed as either a trait or as a state, previous studies on self-reported empathy and aging yielded mixed results, suggesting either age-related stability in empathy (Beadle, Sheehan, Dahlben, \& Gutchess, 2013), as well as higher (O’Brien, Konrath, Grühn, \& Hagen, 2012) or lower empathy scores in older adults (Schieman \& van Gundy, 2000). We found that in the older adult group, higher empathy scores correlated positively with higher accuracy when identifying nonliteral intentions. Schofield, Coles, and Gibb (2007) found that individuals with higher levels of empathy are better at recognizing emotional cues most likely due to their elevated attention to others' feelings in order to determine their own reactions in a situation. Thus, a highly empathic person may pay more attention to communicative cues in order to relate to and understand someone's feelings. This follows our findings of perspective taking scores positively correlating with accuracy of identifying teasing statements and the idea that (older) adults who properly comprehend others' thoughts and feelings tend to be more accurate at also detecting their intentions (Sze et al., 2012).

However, it is possible that the age differences in empathy in our work are the result of the specific cohort rather than age effects (Richter \& Kunzmann, 2011). In order to gain more information about the effect of age and personality on speaker belief, we conducted a mediation analysis. The results suggest that the speaker belief accuracy can in part be explained by a mediation of perspective taking, in the case of teasing, and personal distress, in the case of sarcasm. A similar result was found by Phillips and colleagues (2015) who report that age differences in sarcasm perception were mediated by the ability to perceive facial expressions of emotion. Additionally, the use of self-report measures of empathy as in the current study has been a topic of debate. In contrast to performance-based tasks, self-reported scores might 
reflect the desire to identify oneself and to be seen by others as empathetic and might not represent an effective measure of somebody's real empathy skills (Richter \& Kunzmann, 2011).

Counter to our predictions, we did not find a correlation between the ability to identify nonliteral statements as literal and trait anxiety scores. Research by Milanowicz and colleagues (2017) showed that higher levels of anxiety were a moderate predictor for the willingness to use nonliteral communication, possibly indicating an inclination towards nonliteral communicative styles. Future research should include performance-based empathy and anxiety measures and explore the influence of other aspects that could explain the differences between cohorts, such as gender (Sutterby, Bedwell, Passler, Deptula, \& Mesa, 2012), socio-economic status (Schieman \& van Gundy, 2000), age of the observed actors in the stimuli (Wieck \& Kunzmann, 2015) or life satisfaction (Grühn, Rebucal, Diehl, Lumley, \& Labouvie-Vief, 2008). Additionally, future work should address and compare similar tools that assess social cognition in older adults to the RISC database to further the database's concurrent validity.

Our results showed that older adults with higher personal distress scores tended to be better at identifying sarcastic interactions as nonliteral. Personal distress refers to the uneasiness caused by another person's' negative emotions (Batson, 1991; Eisenberg \& Eggum, 2009). The sarcasm depicted in the RISC videos conveys negative affect and body language, and this type of sarcasm is often perceived as rude (Nakassis \& Snedeker, 2002) or interpreted as antisocial behavior (Bollich et al., 2016). Thus, it is possible that individuals with higher levels of personal distress are more sensitive to the negative emotional cues used in portraying sarcasm (see also research on negativity bias and personal distress; Perry, Hendler, \& Shamay-Tsoory, 2011; Taylor, 1991). Although the correlation between personal distress and identifying sarcasm was only moderate, we also found a significant difference in personal distress scores between the three age groups, prompting future work to explore the role of personal distress in nonliteral communication. These results are especially interesting in the context of the positivity bias that has been suggested to increase with age. The bias would 
predict that older adults are better at identifying teasing statements when compared to sarcasm statements, which is not the case. It appears that in our sample a negative bias, as suggested by higher personal distress scores, leads to gains in identifying nonliteral language. Further studies are needed to specifically test positive and negative biases concerning social-emotional stimuli and the impact on sarcasm and teasing comprehension along the life span.

One of the limitations of our study is that participants gave us information about their cognitive status via self-report, and we cannot rule out the presence of mild cognitive impairment in the aging cohort. While we do not think this was the case, future studies will profit from more careful cognitive and neuropsychological assessments. Additionally, the number of items per speech act type is not perfectly balanced in the current study and this might have skewed the data (see Appendix): while some items are asking about the speaker in the first person ("Would you like some of the cookies I just made?"), other items ask about the inferred state of others ("Do you think people will like my cake?"). Future studies should control for speech act type and study if there are differences in ratings based on this distinction.

\section{Conclusions}

Our findings are consistent with the idea that age-related differences impact the processes of evaluating social intentions (Philips et al., 2015; Pomareda et al., 2019). Overall, young adults were able to correctly identify literal from nonliteral interactions. However, older adults had more difficulties identifying teasing as nonliteral, with differences partly explained by empathy measures. The Tinge Hypothesis could not be confirmed, as all age groups interpreted teasing statements as more friendly when compared to literal negative statements. The results reveal the potential of the RISC database as a sensitive research tool for studying social communication in adults and perhaps in age-related neurodegenerative disorders such as Parkinson's disease (Pell et al., 2014) and frontotemporal dementia (Kipps et al., 2009) where impairments in ToM and perspective taking have been reported. Future studies should focus on 
the consequences of changes in nonliteral language perception in older age, and further examine the influence on social well-being and relationships.

\section{References}

Allen, R., \& Brosgole, L. (1993). Facial and auditory affect recognition in senile geriatrics, the normal elderly and young adults. International Journal of Neuroscience, 68(1-2), 33-42.

Amin, N., Foa, E. B., \& Coles, M. E. (1998). Negative interpretation bias in social phobia. Behaviour research and therapy, 36(10), 945-957.

Bailey, P. E., Henry, J. D., \& von Hippel, W. H. (2008). Empathy and social functioning in late adulthood. Aging \& Mental Health, 12, 499 503. doi:10.1080/13607860802224243.

Bailey, P. E., Henry, J. D. (2008). Growing less empathic with age: Disinhibition of the selfperspective. Journal of Gerontology, 63, 219-2.

Baron, R. M., \& Kenny, D. A. (1986). The moderator-mediator variable distinction in social psychological research: Conceptual, strategic, and statistical considerations. Journal of Personality and Social Psychology, 51(6), 1173.

Bates, D., Mächler, M., Bolker, B., \& Walker, S. (2014). Fitting linear mixed-effects models using Ime4. arXiv preprint arXiv:1406.5823.

Batson, C. D. (1991). The altruism question: Toward a social-psychological answer. Hillsdale, NJ: Erlbaum.

Beadle, J. N., Paradiso, S., Kovach, C., Polgreen, L., Denburg, N. L., \& Tranel, D. (2012). Effects of age-related differences in empathy on social economic decision-making. International Psychogeriatrics, 24(5), 822-833.

Beadle, J. N., Sheehan, A. H., Dahlben, B., \& Gutchess, A. H. (2013). Aging, empathy, and prosociality. Journals of Gerontology Series B: Psychological Sciences and Social Sciences, 70(2), 213-222. 
Bollich, K. L., Doris, J. M., Vazire, S., Raison, C. L., Jackson, J. J., \& Mehl, M. R. (2016). Eavesdropping on character: Assessing everyday moral behaviors. Journal of Research in Personality, 61, 15-21.

Bozdogan, H. (1987). Model selection and Akaike's information criterion (AIC): The general theory and its analytical extensions. Psychometrika, 52(3), 345-370.

Brickman, P., Rabinowitz, V. C., Karuza, J., Coates, D., Cohn, E., \& Kidder, L. (1982). Models of helping and coping. American Psychologist, 37(4), 368-384.

Channon, S., Pellijeff, A., \& Rule, A. (2005). Social cognition after head injury: Sarcasm and theory of mind. Brain and Language, 93(2), 123-134.

Caucci, G. M., \& Kreuz, R. J. (2012). Social and paralinguistic cues to sarcasm. Humor, 25(1), 1-22.

Coles, M. E., Heimberg, R. G., \& Schofield, C. A. (2008). Interpretation of facial expressions and social anxiety: Specificity and source of biases. Cognition and Emotion, 22(6), 1159-1173.

Colston, H. L. (1997). Salting a wound or sugaring a pill: The pragmatic functions of ironic criticisms. Discourse Processes, 23, 24-45

Culpeper, J. (2015). Impoliteness. The International Encyclopedia of Language and Social Interaction, 1-5.

Davis, M. H. (1983). Measuring individual differences in empathy: Evidence for a multidimensional approach. Journal of Personality and Social Psychology, 44(1), 113.

Dews, S., Kaplan, J., \& Winner, E. (1995). Why not say it directly? The social functions of irony. Discourse Processes, 19(3), 347-367.

Dews, S., \& Winner, E. (1995). Muting the meaning A social function of Irony. Metaphor and Symbol, 10(1), 3-19.

Dews, S., \& Winner, E. (1997). Attributing meaning to deliberately false utterances: The 
case of irony. In Advances in Psychology (Vol. 122, pp. 377-414). North-Holland.

Dews, S., \& Winner, E. (1999). Obligatory processing of literal and nonliteral meanings in verbal irony. Journal of Pragmatics, 31(12), 1579-1599.

Eisenberg, N., \& Eggum, N. D. (2009). Empathic responding: Sympathy and personal distress. The Social neuroscience of Empathy, 6, 71-83.

El Haj, M., \& Antoine, P. (2018). Relationship between Lower Tendency to Deceive in Aging and Inhibitory Compromise. Gerontology, 64(1), 67-73.

Elamin, M., Pender, N., Hardiman, O., \& Abrahams, S. (2012). Social cognition in neurodegenerative disorders: a systematic review. J Neurol Neurosurg Psychiatry, jnnp-2012.

Fein, O., Yeari, M., \& Giora, R. (2015). On the priority of salience-based interpretations: The case of sarcastic irony. Intercultural Pragmatics, 12(1)

Gibbs, R. (1994). Figurative Thought and Figurative Language. MA Gernsbacher (ed.) Handbook of Psycholinguistics. 411-446.

Giora, R. (1997). Understanding figurative and literal language: The graded salience hypothesis. Cognitive Linguistics (includes Cognitive Linguistic Bibliography), 8(3), 183-206.

Giora, R., Fein, O., \& Schwartz, T. (1998). Irony: grade salience and indirect negation. Metaphor and Symbol, 13(2), 83-101.

Giora, R., Fein, O., Laadan, D., Wolfson, J., Zeituny, M., Kidron, R., ... \& Shaham, R. (2007). Expecting irony: Context versus salience-based effects. Metaphor and Symbol, (2), 119-146.

Grainger, S. A., Henry, J. D., Naughtin, C. K., Comino, M. S., \& Dux, P. E. (2018). Implicit false belief tracking is preserved in late adulthood. Quarterly Journal of Experimental Psychology,

Grice, H. P. (1975). Logic and conversation. In P. Cole \& J. L. Morgan (Eds.), Syntax and semantics; Vol. 3. Speech Acts (pp. 41-58). New York: Academic Press. 
Grühn, D., Rebucal, K., Diehl, M., Lumley, M., \& Labouvie-Vief, G. (2008). Empathy across the adult lifespan: Longitudinal and experience-sampling findings. Emotion, 8(6), 753.

Halberstadt, J., Ruffman, T., Murray, J., Taumoepeau, M., \& Ryan, M. (2011). Emotion perception explains age-related differences in the perception of social gaffes. Psychology and Aging, 26(1), 133.

Happé, F. G., Winner, E., \& Brownell, H. (1998). The getting of wisdom: theory of mind in old age. Developmental Psychology, 34(2), 358.

Happé, Grühn, D., Rebucal, K., Diehl, M., Lumley, M., \& Labouvie-Vief, G. (2008). Empathy across the adult lifespan: Longitudinal and experience-sampling findings. Emotion, 8(6), 753.

Harris, P. A., Taylor, R., Thielke, R., Payne, J., Gonzalez, N., \& Conde, J. G. (2009). Research Electronic Data Capture (REDCap)—a metadata-driven methodology and workflow process for providing translational research informatics support. Journal of Biomedical Informatics, 42(2), 377-381.

Haverkate, H. (1990). A speech act analysis of irony. Journal of Pragmatics, 14(1), 77-109. https://doi.org/10.1016/0378-2166(90)90065-L

Holtgraves, T., \& Cadle, C. (2016). Communication impairment in patients with Parkinson's disease: Challenges and solutions. J. Parkinsonism Restless Legs Syndr, 6, 45-55.

Jakobson, L. S., Pearson, P. M., Kozub, Z., Hare, C., \& Rigby, S. N. (2018). Links between traits associated with the broad autism phenotype and empathy and young adults' ability to decode speaker intentionality. Research in Autism Spectrum Disorders, $50,11-21$.

Jarvis, S. N., \& Miller, J. K. (2017). Self-projection in younger and older adults: a study of episodic memory, prospection, and theory of mind. Aging, Neuropsychology, and Cognition, 24(4), 387-407.

Jorgensen, J. (1996). The functions of sarcastic irony in speech. Journal of 
Pragmatics, 26(5), 613-634.

Keltner, D., Capps, L., Kring, A. M., Young, R. C., \& Heerey, E. A. (2001). Just teasing: a conceptual analysis and empirical review. Psychological Bulletin, 127(2), 229.

Kipps, C. M., Nestor, P. J., Acosta-Cabronero, J., Arnold, R., \& Hodges, J. R. (2009). Understanding social dysfunction in the behavioural variant of frontotemporal dementia: the role of emotion and sarcasm processing. Brain, 132(3), 592-603.

Kiss, I., \& Ennis, T. (2001). Age-related decline in perception of prosodic affect. Applied Neuropsychology, 8(4), 251-254.

Kizach, J. (2014). Analyzing Likert-scale data with mixed-effects linear models: a simulation study. Poster Presented at Linguistic Evidence.

Kuznetsova, A., Brockhoff, P. B., \& Christensen, R. H. B. (2017). ImerTest package: tests in linear mixed effects models. Journal of Statistical Software, 82(13).

Lampert, M. D., \& Ervin-Tripp, S. M. (2006). Risky laughter: Teasing and self-directed joking among male and female friends. Journal of Pragmatics, 38(1), 51-72.

Leggitt, J. S., \& Gibbs, R. W. (2000). Emotional reactions to verbal irony. Discourse processes, 29(1), 1-24.

Lenth, R. (2018). Emmeans: Estimated marginal means, aka least-squares means. R Package Version, 1(2).

Mather, M., \& Carstensen, L. (2003). Aging and attentional biases for emotional faces. Psychological Science, 14(5), 409-415.

Maylor, E. A., Moulson, J. M., Muncer, A. M., \& Taylor, L. A. (2002). Does performance on theory of mind tasks decline in old age? British Journal of Psychology, 93(4), 465-485.

Mewhort-Buist, T. A., \& Nilsen, E. S. (2013). What are you really saying? Associations between shyness and verbal irony comprehension. Infant and Child Development, 22(2), 180197.

Mewhort-Buist, T. A., \& Nilsen, E. S. (2019). Shy children's understanding of irony: Better 
comprehension does not always mean better socioemotional functioning. Infant and Child Development, 28(3), e2131.

Mikulincer, M., Shaver, P. R., \& Pereg, D. (2003). Attachment theory and affect regulation: The dynamics, development, and cognitive consequences of attachmentrelated strategies. Motivation and Emotion, 27(2), 77-102.

Milanowicz, A., Tarnowski, A., \& Bokus, B. (2017). When sugar-coated words taste dry: The relationship between gender, anxiety, and response to irony. Frontiers in psychology, 8 , 2215.

Mitchell, R. L. (2007). Age-related decline in the ability to decode emotional prosody: primary or secondary phenomenon?. Cognition and Emotion, 21(7), 1435-1454.

Nakassis, C., \& Snedeker, J. (2002). Beyond sarcasm: Intonation and context as relational cues in children's recognition of irony. In Proceedings of the twentysixth Boston University conference on language development. Cascadilla Press, Somerville, MA (pp. 429-440).

Norman, G. (2010). Likert scales, levels of measurement and the "laws" of statistics. Advances in health sciences education, 15(5), 625-632.

O’Brien, E., Konrath, S. H., Grühn, D., \& Hagen, A. L. (2012). Empathic concern and perspective taking: Linear and quadratic effects of age across the adult life span. Journals of Gerontology Series B: Psychological Sciences and Social Sciences, 68(2), 168-175.

Orbelo D, Testa J, Ross E. (2003) Age-related impairments in comprehending affective prosody with comparison to brain damaged sub- jects. Journal of Geriatric Psychiatry and Neurology, 16,44-5.

Orbelo, D. M., Grim, M., Talbott, R., \& Ross, E. (2005). Impaired comprehension of affective prosody in elderly subjects is not predicted by age-related hearing loss or age-related 
cognitive decline. Journal of Geriatric Psychiatry and Neurology, 18, 25-32. doi:10.1177/ 0891988704272214

Pell, M. D., Monetta, L., Rothermich, K., Kotz, S. A., Cheang, H. S., \& Mcdonald, S. (2014).

Social Perception in Adults With Parkinson's Disease. Neuropsychology, 28(6), 905-

916.

Perry, D., Hendler, T., \& Shamay-Tsoory, S. G. (2011). Can we share the joy of others? Empathic neural responses to distress vs joy. Social Cognitive and Affective Neuroscience, 7(8), 909-916.

Pexman, P. M., \& Olineck, K. M. (2002). Does sarcasm always sting? Investigating the impact of ironic insults and ironic compliments. Discourse Processes, 33(3), 199-217.

Phillips, L. H., Bull, R., Allen, R., Insch, P., Burr, K., \& Ogg, W. (2011). Lifespan aging and belief reasoning: Influences of executive function and social cue decoding. Cognition, 120(2), 236-247.

Phillips, L. H., Allen, R., Bull, R., Hering, A., Kliegel, M., \& Channon, S. (2015). Older adults have difficulty in decoding sarcasm. Developmental Psychology, 51(12), 1840.

Phillips, L. H., Slessor, G., Bailey, P. E., \& Henry, J. D. (2014). Older adults' perception of social and emotional cues. 9-25.

Pomareda, C., Simkute, A., \& Phillips, L. H. (2019). Age-related differences in the ability to decode intentions from non-literal language. Acta psychologica, 198, 102865.

Reed, A. E., \& Carstensen, L. L. (2012). The theory behind the age-related positivity effect. Frontiers in psychology, 3, 339.

Richter, D., \& Kunzmann, U. (2011). Age differences in three facets of empathy: Performance-based evidence. Psychology and Aging, 26(1), 60.

Rothermich, K., \& Pell, M. D. (2015). Introducing RISC: A new video inventory for testing social perception. PloS one, 10(7), e0133902.

Sutterby, S. R., Bedwell, J. S., Passler, J. S., Deptula, A. E., \& Mesa, F. (2012). Social 
anxiety and social cognition: The influence of sex. Psychiatry Research, 197(3), 242245.

Satterthwaite, F. E. (1946). An approximate distribution of estimates of variance components. Biometrics Bulletin, 2(6), 110-114.

Schieman, S., \& Van Gundy, K. (2000). The personal and social links between age and self-reported empathy. Social Psychology Quarterly, 152-174.

Schofield, C. A., Coles, M. E., \& Gibb, B. E. (2007). Social anxiety and interpretation biases for facial displays of emotion: Emotion detection and ratings of social cost. Behaviour Research and Therapy, 45(12), 2950-2963.

Schwoebel, J., Dews, S., Winner, E., \& Srinivas, K. (2000). Obligatory processing of the literal meaning of ironic utterances: Further evidence. Metaphor and Symbol, 15(1-2), 47-61.

Shamay-Tsoory, S. G., Tomer, R., \& Aharon-Peretz, J. (2005). The neuroanatomical basis of understanding sarcasm and its relationship to social cognition. Neuropsychology, 19(3), 288.

Shammi, P., \& Stuss, D. T. (2003). The effects of normal aging on humor appreciation. Journal of the International Neuropsychological Society, 9(6), 855-863.

Spielberger, C.D., Gorsuch, R.L., Lushene, R., Vagg, P.R., \& Jacobs, G.H. (1983).

Manual for the State-Trait Anxiety Inventory. Palo Alto, CA: Consulting Psychologists Press.

Sullivan, S., \& Ruffman, T. (2004). Emotion recognition deficits in the elderly. International Journal of Neuroscience, 114(3), 403-432.

Sze, J. A., Gyurak, A., Goodkind, M. S., \& Levenson, R. W. (2012). Greater emotional empathy and prosocial behavior in late life. Emotion, 12(5), 1129-1140.

Taghavi, M. R., Moradi, A. R., Neshat-Doost, H. T., Yule, W., \& Dalgleish, T. (2000). Interpretation of ambiguous emotional information in clinically anxious children and 
adolescents. Cognition \& Emotion, 14(6), 809-822.

Taylor, S. E. (1991). Asymmetrical effects of positive and negative events: the mobilization-minimization hypothesis. Psychological Bulletin, 110(1), 67.

Team, R. C. (2018). R: A language and environment for statistical computing.

Thompson, D., Mackenzie, I. G., Leuthold, H., \& Filik, R. (2016). Emotional responses to irony and emoticons in written language: evidence from EDA and facial EMG. Psychophysiology, 53(7), 1054-1062.

Tingley, D., Yamamoto, T., Hirose, K., Keele, L., \& Imai, K. (2014). Mediation: R package for causal mediation analysis.

Uekermann, J., Thoma, P., \& Daum, I. (2008). Proverb interpretation changes in aging. Brain and Cognition, 67(1), 51-57.

Valuch, C., Pflüger, L. S., Wallner, B., Laeng, B., \& Ansorge, U. (2015). Using eye tracking to test for individual differences in attention to attractive faces. Frontiers in Psychology, 6, 42.

West, R., \& Covell, E. (2001). Effects of aging on event-related neural activity related to prospective memory. Neuroreport, 12(13), 2855-2858.

Wieck, C., \& Kunzmann, U. (2015). Age differences in empathy: Multidirectional and contextdependent. Psychology and Aging, 30(2), 407.

Winton, E. C., Clark, D. M., \& Edelmann, R. J. (1995). Social anxiety, fear of negative evaluation and the detection of negative emotion in others. Behaviour Research and Therapy, 33(2), 193-196.

Yorkston, K. M., Bourgeois, M. S., \& Baylor, C. R. (2010). Communication and aging. Physical Medicine and Rehabilitation Clinics, 21(2), 309-319. 
Supplement 1. Descriptions of scenes.

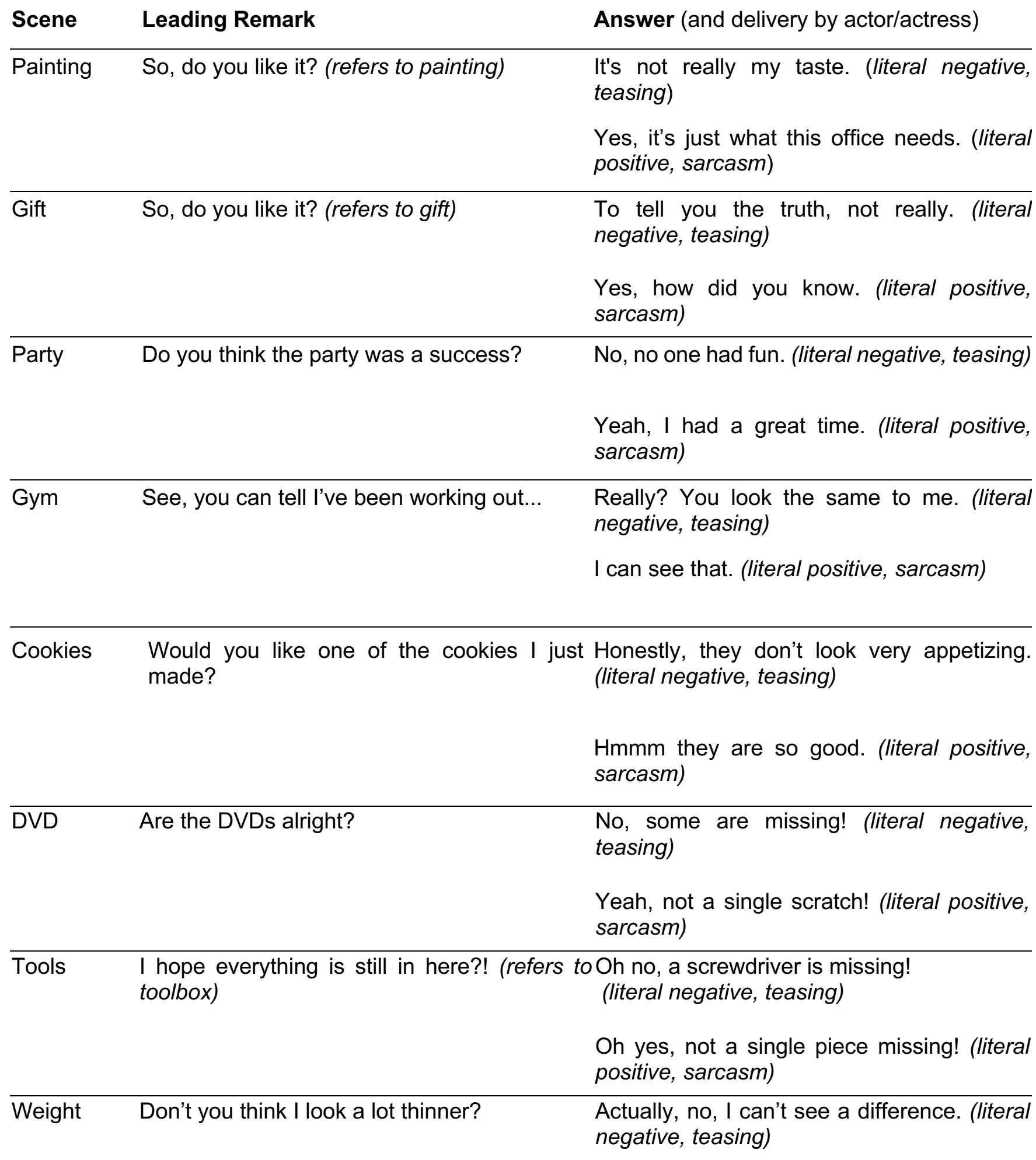


Yes, you look like an entirely different person!

(literal positive, sarcasm)

Jewelry Do you think it's too much? (refers to jewelry) I think it's a bit too much. (literal negative, teasing)

I think it looks very nice. (literal positive, sarcasm)

Book Oh, did you like it? (refers to book)

Honestly, it was a pain to read. (literal negative, teasing)

I thought it was awesome. (literal positive, sarcasm)

Cake Do you think people will like my cake?

Honestly, it doesn't look very good. (literal negative, teasing)

It looks really yummy! (literal positive, sarcasm)

Specialty This is a specialty in Sweden, my parents brought it, what do you think?

It has a funny taste. (literal negative, teasing)

Oh my god, it's delicious. (literal positive, sarcasm)

Supplement 2. Video screenshot for the scene "party".

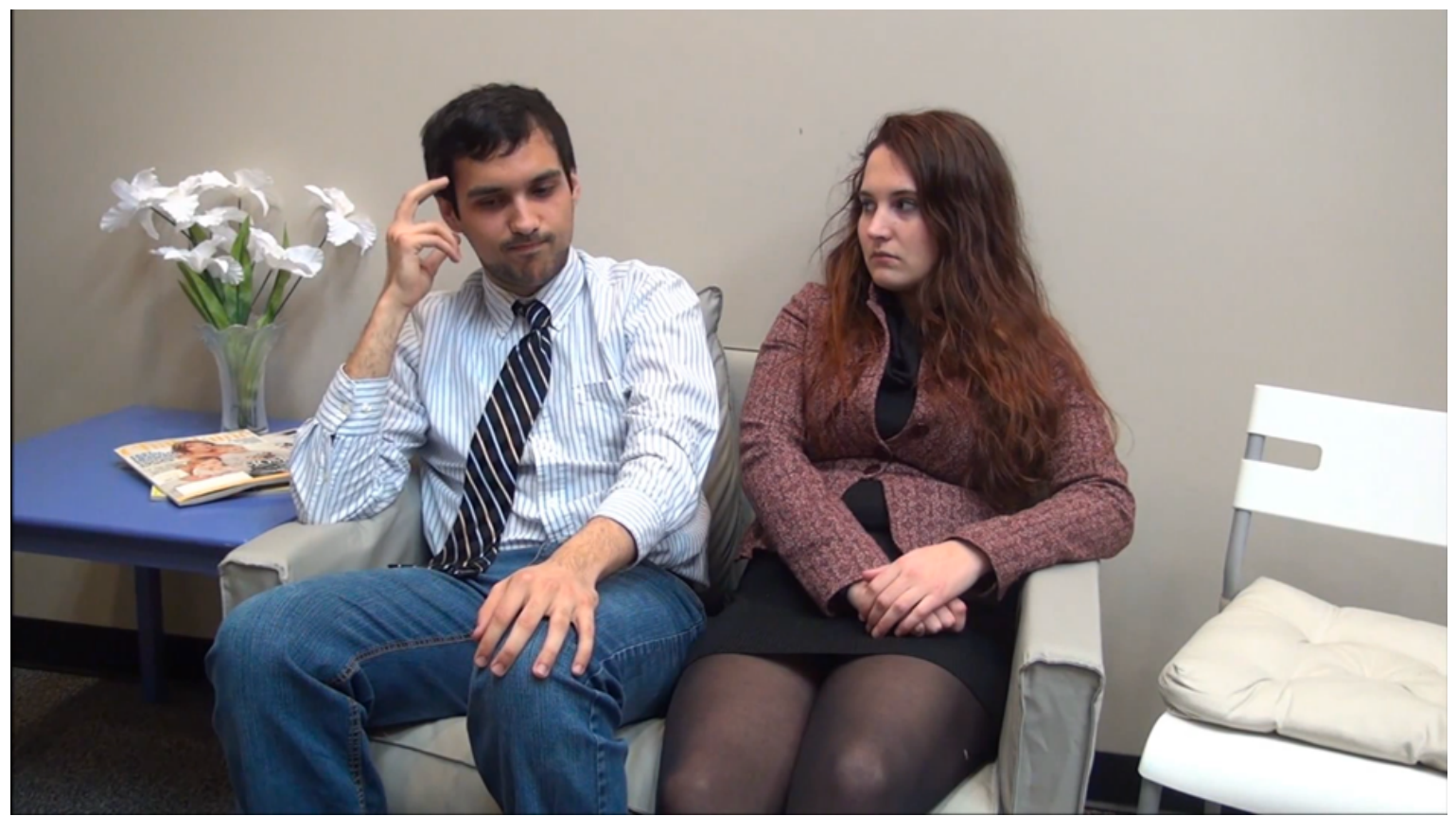

